\title{
Contornos da poesia em Nuno Júdice
}

Rogério Barbosa da Silva Centro Federal de Educação Tecnológica de Minas Gerais

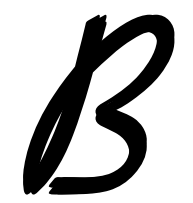

usca-se, neste trabalho, uma leitura da poesia mais recente de Nuno Júdice, em que se pode estabelecer uma reflexão sobre a relação existente entre os processos da lírica na contemporaneidade e o aproveitamento das experiências do sujeito, algo que se pretende verificar na aproximação entre os livros Linhas de Água (2000) e Guia de Conceitos Básicos (2010). Nessa relação, entende-se que essa poesia conjuga a tradição literária e os próprios processos de fabulação como proposta de construção de uma voz singular e de uma poética (possível) na modernidade.

Para essa compreensão, é preciso pensar que a poesia de Júdice tem como traço fundamental, como já assinalou Américo António Lindeza Diogo, a reordenação diversa dos elementos que a tradição ocidental lhe legou e que, assim, ela afirma, a um só tempo, a descrença nos poemas e a conseqüência da adoção da atitude, menos do poeta do que de uma voz. ${ }^{1} \mathrm{Um}$ "tom de voz que multiplica a contradição ofegante das nostalgias", diria o próprio Júdice num poema de 1982.

Por outro lado, observa-se que sua poesia busca um minerar da subjetividade, descartando o jogo ilusório que se caracteriza ao mesmo tempo por um exercício de busca e de recusa, como se observa no poema "Existência submarina", de

${ }^{1}$ DIOGO, 1993, p. 56. 
Linhas de água. Ou ainda uma poética, em que o trabalho do poeta é um exercício que se tenta imprimir às perplexidades do sujeito ante o mundo e as coisas, as mais simples, sobre o contínuo movimento do poema, as suas linhas de fuga, que se reverberam e fazem as suas próprias imagens instáveis se abrirem para um mundo só aparentemente translúcido. É como diz Ida Alves, quando afirma a propósito desse poeta, um homem de letras, que vive a literatura nas suas múltiplas dimensões, seja da poesia, da prosa, da crítica ou do ensino, já que é também professor:

A poesia é o espelho em que o sujeito se mira sempre em busca da imagem outra que o puro reflexo oculta. Assim, essa escrita obcecada fala do tempo e da divisão do ser, motivando a reflexão metafísica, a discussão sobre o conhecimento que a linguagem poética pode proporcionar. ${ }^{2}$

Ao pensar em Linhas de água (2000), seríamos levados, em princípio, a pensar as coisas em sua própria superfície, num estar diante delas, rente a elas, o que parece demonstrar que o possível mistério que a vida possa trazer não se coloca numa dimensão profunda do eu; antes está tudo no plano da existência, em que o sujeito interage com o mundo e suas formas. No dizer de outro poeta, crítico e professor, Manuel Gusmão, a poesia assim posta nos faz pensar numa "voz escrita, inscrita e excrita - tatuagem e palimpsesto". Por conseguinte, a pele, do sujeito, do papel e, quiçá, as linhas de água, é onde se inscreve o múltiplo, o instável ou as camadas do tempo. Para Gusmão,

(...) somos feitos e desfeitos pelo poieín das artes: pela poesia...; pelo romance em que procuramos os nossos possíveis; pelas cenas onde corpos e vozes ardem à nossa vista; pelos filmes que nos correm no sangue; pela música

2 ALVES, 2010, p. 316. 
que nos sopra os ventos nas árvores do cérebro; pelas fotografias em que ficamos para sempre (junto a) uma rocha batida pelas ondas; pela escultura em que tacteamos o desabamento e o voo do mundo; por essa dança que nos desenha no ar, enquanto dançamos à beira do vulcão; pelas palavras que um dia nos disseram ou não disseram, por tudo aquilo que escolhe ou nos escolheu; ou por aquela lettera amorosa que lemos e relemos e contudo não chegou a ser lida, nem enviada. ${ }^{3}$

Os cerca de trinta poemas de Linhas de água, com suas dez linhas que orientam e reúnem os poemas em seus movimentos próprios e em torno do eixo do livro, apontam bem essas considerações que viemos traçando até aqui. Assim, o poema que serve de pórtico descreve-nos um estado de busca, em que o poeta procura no chão "as linhas que conduzem ao centro", segue atrás de um "carreiro de formigas" ao encontro dos traços no meio das ervas. Observa-se que supõe de partida que é possível que o exercício poético possa revelar aquilo que subjaz à linguagem:

O campo, no inverno, é assim: colinas nítidas por entre uma rede de ramos secos que prendem os pássaros, como peixes, sob a água fria das nuvens. Apanho-os das árvores com facilidade; no inverno, os pássaros não têm sombra, e o caçador sabe onde se escondem, mesmo que o seu canto só se ouça por dentro de um esvoaçar de memórias. ${ }^{4}$

O centro, porém, que no poema "Floral", logo a seguir, condiz com "a pura expressão de imortalidade", vai se tornando difuso, mesmo porque o poema, ainda que, tal como os pássaros, possa perder sua sombra, ao se tornar nítido contém ainda algum obstáculo à sua compreensão:

${ }^{3}$ GUSMÃO, 2010, p. 11.

${ }^{4}$ JÚDICE, 2000, p. 1031. 


\section{Linha 1}

Cada poema tem uma sombra. Estendo as mãos e posso tocá-la, como se toca a sombra de uma árvore que foge de nós quando procuramos o seu abrigo. Assim, o poema é um jogo de luz: e a sua sombra recua e avança de acordo com a hora do dia.

No fim do poema, a sombra como que desaparece. $\mathrm{O}$ poema fica a prumo; e o meio-dia salta de dentro dele, com a sua luz inteira, como se o poema fosse uma realidade transparente e se pudesse olhar, através dele, a circunferência do mundo. ${ }^{5}$

O jogo então se desenrola no exercício da linguagem: as palavras mudam de cor; as frases empalidecem quando o sol as deixa, de modo que o poeta precisa fazer com que o poema respire o ar da manhã: "convém deixar a luz para dentro das páginas. O negro da impressão poderá brilhar em excesso; e o branco do papel reflectir o céu. O que está escrito, embebido desse fogo, fixar-se-á na nossa memória [...]". ${ }^{6}$

Cada movimento contém o seu próprio ciclo, e também implica uma relação com o outro, como dirá o poeta em "Existência submarina":

Entreabro a água, se se pode dizer

que a água se entreabre como se entre-

abre uma porta, uma vida, ou

o coração, que está normalmente fechado

naquilo a que se chama

a caixa do peito. Mas a água, se a entreabro,

é porque no seu fundo há olhos que estão abertos

com a corrente: procuram os meus, que

${ }^{5}$ JÚDICE, 2000, p. 1033.

${ }_{6}^{6}$ JÚDICE, 2000, p. 1034. 
no entanto, dentro de água, são os olhos cegos, e tentam contar-me o que se passa no fundo, (...)

\section{Depois,}

Volto a fechar a água. Não quero que esses olhos vejam para além da superfície, nem que eles me persigam quando atravesso a rua, para comprar o jornal, e os meus olhos se cruzam com os teus, cujo amor desejo, embora não saiba se és tu, de facto, aquela com quem me cruzo, todos os dias $(\ldots)^{7}$

Ao contrário da linha da água, cuja superfície se coloca como limite do olhar para o poeta, o poema tem uma dimensão translúcida, embora labiríntica. Será o movimento da Linha 2:

O poema é o espelho do poema. Ao escrevê-lo, atravesso a página, côo se atravessa o vidro do espelho, e entro num mundo de que só consigo sair quando chego ao fim do poema. ${ }^{8}$

Assim, ao visitar o atelier de Cézanne ("No Ateliê de Cézanne), o poeta percebe que a matéria, não só se transforma em contato com o tempo e com o ar, atestando sua efemeridade, como também, de alguma forma, conserva o espírito do que ali existiu, embora permaneça intocável: "Só o ar, que se deixa tocar como/ um objecto, muda o sentido das coisas / entre um abrir e fechar/ de janelas". 9

Em Linha 3, as oscilações do sentido se deixam levar pela polifonia própria da linguagem: o risco no papel, as linhas do poema, as linhas negras no mapa da cidade, as linhas do

\footnotetext{
7 JÚDICE, 2000, p. 1035.

8 JÚDICE, 2000, p. 1036.

9 JÚDICE, 2000, p. 1037.
} 
eléctrico ou as linhas dos carris que ligam uma estação a outras, e a indecisão do poeta: Mas qual dessas linhas tomar? No entanto, a máquina, representação do comboio ou do eléctrico, repentinamente se transforma no próprio poema, no seu maquinismo vocal que passa a afetar a paisagem: “Então, a máquina sai de dentro da cabeça, atravessa as paredes do quarto, e perde-se na voz que diz o poema - a única voz que rompe o silêncio da manhã." 10

Interessante, para nós, é observar que a poesia de Nuno Júdice, nesse livro, mostra o trânsito livre entre o mundo interior e o exterior, embora cada coisa, cada pensamento sejam deslocados ao serem tocados pela poesia. Isso é o que se pode observar, por exemplo, no penúltimo poema do livro, cujo título é "Poética (alegoria):

À tarde, ao entrar em casa, com os olhos carregados do sol que bate nas pedras, fazendo rebrilhar o chão, o interior torna-se obscuro como o sentido do poema. Avanço, então, como se não soubesse o caminho; e quase não reconheço móveis, ângulos de esquina, portas que não se vê se estão abertas ou fechadas. A partir de certa altura, porém os olhos habituam-se: e tudo surge nítido, familiar, com os objectos nos lugares em que deviam estar. Isto não quer dizer que se reaja como antes: as mãos ainda procuram apoios, e uma sensação de vertigem acompanha a localização das coisas. Depois, ao voltar a sair de casa para a rua, onde a força do sol aumenta como o meio-dia, a cegueira é inversa, com os olhos ofuscados - tal como, ao sair do

${ }^{10}$ JÚDICE, 2000, p. 1039. 
poema, o mundo parece empurrar-nos para dentro, e nos exclui de uma claridade que se tornou inútil. Com efeito, também o cego profeta dispensa os olhos para adivinhar o destino; e a leitura do poema, por vezes, substitui o conhecimento da vida, a que também se chama: a visão do mundo. ${ }^{11}$

Já nesse poema, evidencia-se que o pensamento preside a poesia de Nuno Júdice, na medida em que seus poemas atestam a preocupação tanto com a sua elaboração formal quanto com o lugar do poeta em sua dupla condição de leitor crítico e criador. No entanto, pela condição própria do poema, trata-se de um pensamento difuso que se faz por via da metáfora e cuja recepção torna-se também tangencial, indireta. A experiência poética transforma o seu objeto, o poema, toca as coisas e o próprio sujeito seja leitor ou autor. Portanto, é interessante que nessa alegoria poética o poeta entra numa zona imprecisa (o interior torna-se obscuro como o sentido do poema) e ao sair, a clareza supostamente adquirida torna-se inútil. Resta a experiência do poético, única possibilidade de adquirir certo conhecimento da vida.

Talvez, por isso, insiste o poeta nessa mesma senda em livros mais recentes, como Guia de conceitos básicos (2010), ainda que possamos perceber de livro a livro alterações substanciais na modulação do verso e dessa voz singular que sua lírica tanto busca. Essa lírica singular, conforme buscamos demonstrar, resulta tanto de um trabalho formal, que depura a linguagem, quanto também de uma espécie outra de decantação, que nos faz distinguir a experiência poética da experiência imediata do sujeito, como se vê nessa estrofe de "Reminiscência":

${ }^{11}$ JÚDICE, 2000, p. 1059. 


\section{Um silêncio clama a recompensa}

de um calor intenso como a palavra que nele

ficou, até hoje, quando a tiro de dentro das cinzas

e a limpo de inúteis significados, para que

só o amor lhe dê a forma exacta como

a pedra deste canto, e a transforme num som

transparente como a água, abstracto como o ar, musical como a voz de onde nasceu. ${ }^{12}$

Observe-se que, embora o objeto do poema seja o passado, a reminiscência nostálgica, a poesia que dele deriva tem algo de abstrato ou rarefeito, estando muito mais próxima da fonte do que da "água" que jorra pelo poema. Talvez, pelo fato de essa poesia trazer constantemente um olhar sobre o passado, ou pelo fato de ela também demonstrar uma perspectiva sombria sobre o futuro, mesmo sendo uma legítima herdeira da modernidade, tenha levado muitos a se referirem ao sentido nostálgico de seus poemas, ou, como o fez Lindeza Diogo, tratála como uma espécie de "modernidade anacrônica". Isso ainda faz sentido neste livro, produzido em 2010, o que mostra uma linha coerente da poesia de Nuno Júdice ao longo dos quase quarenta anos de poesia. Aqui também se vive uma "apoteose de cinza", em que o futuro se faz apenas a sina hereditária frustrada do passado. Trata-se de uma experiência do tempo não linear e descontínua, de modo que é no instante, na evanescente experiência estética que se toca o bafo do sublime, a beleza derruída das coisas.

Por outro lado, o poema que dá título ao livro, "Guia de conceitos básicos", em que pese certa ironia aos manuais, levanos a pensar o poema como uma bastilha que nos faz sobreviver a cada dia, como se observa nos versos: "Use o poema para

12 JÚDICE, 2010, p. 134. 
elaborar uma estratégia/de sobrevivência no mapa da sua vida. Recorra/aos dispositivos da imagem, sabendo que/ela lhe dará um acesso rápido aos recursos / da sua alma (...)"13 Evidentemente, esse "Guia" nada tem de prático e isso se desvela no tom irônico de versos como os do final, que, no entanto, não deixam de apontar um possível contato entre sonho e realidade:

\section{(...) Escolha uma superfície}

plana: e deslize o seu olhar pelo

estuário da estrofe, para que ele empurre a corrente das emoções até à foz. Verifique então se todas as opções estão disponíveis: e descubra a data e a hora em que o sonho se converte em realidade, para que poema e vida coincidam. ${ }^{14}$

Nesse livro, essa possível relação entre sonho e realidade mediada pela linguagem poética comparece algumas vezes. Não se trata, porém, de uma evasão do real nem de uma forma mágica de tocar a realidade pela fantasia. Mais provável é se tratar de um hiato, de uma pausa breve em que se descortina uma consciência por trás dos constantes comentários aos fatos e episódios banais ou não de que tratam os poemas de Guia de Conceitos Básicos. Exemplos podem ser analisados em dois poemas: "Os problemas materiais não afectam a composição da obra" e "Diferença entre sonho e realidade". Em ambos, assim como em muitos poemas desse livro, o poeta recorre ao anedótico, ou a uma breve narrativa que funciona como uma parábola invertida. Assim, neste primeiro poema, o poeta comenta uma passagem do $1^{\circ}$ Concerto de Brandeburgo, de J.

13 JÚDICE, 2010, p. 135.

14 JÚDICE, 2010, p. 135. 
S. Bach, acrescido de uma pequena anedota sobre a encomenda não paga deste concerto pelo príncipe, o que talvez explicasse o título do poema, uma vez que o concerto de Bach sobrevive aos tempos, ainda que as necessidades materiais que o levaram a compô-lo não tenham sido satisfeitas. No poema, o que se ressalta é o problema da incomunicabilidade, o traço obscuro, opaco, da linguagem, e que resulta da mudança de ritmo num adágio que se irrompe sobre uma passagem do allegro, com o qual o compositor obriga a quem o segue a uma pausa reflexiva. Diz o poeta:

$$
\text { (...) Mas }
$$

nesse adágio, é como se Bach obrigasse quem o ouvia a fazer uma paragem; e, de súbito, uma desolação entra na música, sem destruir a sua perfeição, tal como o outono também pode trazer uma outra beleza aos campos, quando o céu se cobre de nuvens e as folhas adquirem uma tonalidade ruiva, anunciando o inverno. Porém, esta mudança não dura muito tempo; e logo a paisagem retoma a sua vida, através do allegro em que ressoa um esplendor de grandes salas iluminadas. (...)

\section{(...) Mas nem todos}

o compreenderam; e o que é certo é que o príncipe de brandeburgo não lhe pagou a encomenda. ${ }^{15}$

Como podemos verificar, o poema se constitui sob a forma de um comentário fundamentado na experiência sensível do sujeito em relação à música de Bach e em seus conhecimentos sobre essa música. No entanto, as informações agregadas ao poema, como a encomenda e a não compreensão da atitude do

${ }^{15}$ JÚDICE, 2010, p. 59. 
músico, que não recebe o pagamento pela encomenda, garantem pouquissimamente a compreensão do próprio poema, já que isso aparece descartado desde o título: os problemas materiais não afetam a composição da obra. A lógica paradoxal do músico só é compreendida pela lógica paradoxal do poeta, que vê na desarmonia, para além da irrupção de uma beleza efêmera, a revelação de uma atitude artística consciente e que, assim, repete a incompreensível e transitória beleza presente nas oscilações da natureza. Por conseguinte, a composição da obra segue as suas próprias razões, diferentemente daquelas ditadas pelo pragmatismo, e com isso logra, às vezes, atingir uma ordem natural.

Em "A diferença entre a realidade e o sonho", confirmase uma oposição entre a lógica da imaginação poética e a lógica pragmática. Não há, na verdade, uma coincidência entre sonho e realidade, pois a imaginação poética constrói uma realidade própria, dá vida àquilo que se diz e, de certa forma, exige que o poeta feche os olhos para ver: "quando fechava os olhos, via/ as grandes planícies do sonho encherem-se/de carros de feno, puxados pelos centauros/de uma Grécia envelhecida" ${ }^{16}$ Em contrapartida, a fala ordinária traz consigo uma espécie de irracionalidade:

'Chegaste

à primavera', gritavam-me os camponeses

loucos. E eu explicava-lhes que não: as ceifas

são no verão, e o outono é um

tempo de semear. Eles não ouviam a minha lógica

sazonal, e as suas foices cortavam o ar, como se

aí estivessem as searas maduras do fim do tempo. ${ }^{17}$

16 JÚDICE, 2010, p. 19.

17 JÚDICE, 2010, p. 19. 
Em outras palavras, a perspectiva sazonal do camponês o faz lidar com a noção de um tempo que escorre para um fim: as searas maduras do fim do tempo. A lógica do poeta vê no outono um tempo de semear. Isto é, a poesia pode reviver das cinzas, e o seu tempo é sem cronologia: passado, presente e futuro formam um só tempo, que é o tempo da poesia. Não à toa, o poeta diz em "Imagem teológica":
"Deus onde o fulgor da vida se apagou quando a matilha dos séculos lhe rasgou as veias, e fez correr o rio de palavras que inundou as margens de uma planície de silêncio; cego para as iluminações e surdo aos oráculos; oferece aos ouvidos das estátuas o desafio mudo dos seus lábios secos, descobrindo no filtro dos astros a imagem que um incêndio de números esculpiu nas cinzas da eternidade.
Perdi-o a meio do caminho, no chão dos instantes, por entre as folhas roxas de uma floresta de crepúsculos. ${ }^{18}$

Não há promessas. Não há Deus. Há uma "floresta de crepúsculos". Há as palavras que inundam "planícies de silêncios", há aquelas palavras que se recolhem das cinzas e que, despidas dos inúteis significados, como se diz em "Reminiscências", já referido anteriormente, pode se transformar num "som transparente", "abstracto", "musical".

${ }_{18}^{18}$ JÚDICE, 2010, p. 128. 
Por trás do coloquialismo discursivo e de sua aparente simplicidade e limpidez, a linguagem em Guia de conceitos básicos parece extrair toda a sua força de uma gama de imagens paradoxais, ora temperada pela ironia, ora por uma reflexão metapoética, que contribuem para seu hermetismo, mas também subvertem a lógica flácida da cultura de consumo na contemporaneidade. Pensa-se o sujeito em sua relação com o mundo a partir dos despojos da tradição literária ocidental e das ruínas próprias do mundo contemporâneo. Nesse contexto, a poesia de Nuno Júdice tanto caminha num diálogo com a tradição, desde a antiga Grécia, como Orfeu, passando por tradições mais recentes como a de Shakespeare, Pessoa, Ponge, entre outros, quanto extrai de situações banais cotidianas observações e hipóteses de trabalho, as quais visam pensar a escrita como trabalho. Isso nos faz pensar a poesia como um artifício, sim, mas também como um exercício, isto é, "a mão que percorre as linhas da frase,/ como se fossem as linhas da vida, e decide/em cada cesura um ponto final."19

Enfim, dadas as características sublinhadas acima, é possível pensarmos a poesia de Nuno Júdice a partir do restabelecimento de um diálogo com tradições antigas, a exemplo da Grécia, sem descartar um viés pluralista, ao incorporar o diálogo com os fundadores da modernidade e com as tradições mais recentes da poesia ocidental. Vários traços que se observam nessa poesia de Nuno Júdice foram assinalados por Alfonso Berardinelli como exemplos de como a poesia teria forçado os seus limites na pós-modernidade, isto é,

1) recuperando dimensões da prosa ou, às vezes, da teatralidade; 2) reabrindo o diálogo com a tradição prémoderna; 3) praticando uma pluralidade de vias possíveis

19 JÚDICE, 2010, p. 131. 
e saindo da tutela de poéticas fundadas numa consciência histórica de tipo monista; 4) mantendo, recuperando ou desconstruindo o 'universo humano' da experiência e 'idioleto' estilístico. ${ }^{20}$

De fato, vários aspectos são muito importantes em Guia de conceitos básicos. Destaque-se a narratividade que aproxima sua poesia do diálogo, bem marcado, no entanto, por cesuras e pequenas alterações no andamento rítmico, os quais contribuem para tensionar o pensamento e a expressão poética em seus versos. Destaque-se as inúmeras referências e citações intertextuais com obras de autores díspares como Shakespeare, Ponge, Platão, Michaux, J. S. Bach, Pessoa, Herberto Helder, um halo da tradição romântica alemã, do surrealismo e dos trágicos gregos, entre inúmeras outras referências. Enfim, trata-se de uma poesia que mantém desde $A$ noção do poema (1972) um tenso diálogo com as "gramáticas oficiantes de uma memória ocidental". ${ }^{21}$

Para finalizar, observamos que há uma perspectiva comum quanto ao tratamento da linguagem entre os livros Guia de conceitos básicos e Linhas de água, quando os versos tendem a uma maior simplicidade, aproximam-se do coloquial e dos elementos cotidianos, tendo sempre como ponto de partida a experiência do poeta com o mundo e os livros. No entanto, cresce a complexidade do poema no plano da reflexão sobre a poesia, numa espécie de cifra que se elabora sobre uma aparente legibilidade dos poemas. Isso ocorre porque os sucessivos deslocamentos através das "linhas" em Linhas de água nos revela que a libertação possível não descarta a obscuridade do poema, embora essa obscuridade não se

\footnotetext{
${ }^{20}$ BERARDINELLI, 2007, p.179.

${ }^{21}$ JÚDICE, 1999, p. 11.
} 
instaure no barroquismo da linguagem. O trânsito entre as sensações, $\mathrm{o}$ inconsciente e as coisas e imagens que se apresentam aos nossos sentidos é que se encarrega dessa dimensão obscura da linguagem. Em certa medida, Guia de conceitos básicos estende suas perquirições a esse universo instável, cuja travessia põe lado a lado a beleza clássica e o efêmero da contemporaneidade, o sonho e a realidade, o poema e o poeta... Não se trata, no entanto, de uma simplificação, pois, tal como em Linhas de água, a superfície é o plano em que todas as coisas se misturam e adquirem o seu próprio peso. $\mathrm{O}$ conceito, o manual de instruções, o pensar sobre a linguagem não inibem a obscuridade que cercam a vida e a arte, como ironicamente se coloca no já citado poema Guia de conceitos básicos: "(...) Verifique/ então se todas as opções estão disponíveis: e / descubra a data e a hora em que o sonho / se converte em realidade, para que o poema / e a vida coincidam." 22

Essa coincidência entre realidade e vida também aparece no referido "Poética (alegoria)", em que a leitura do poema é vista como a experiência poética passível de substituir o conhecimento de mundo. Ou seja, jamais o mundo poderá ser desvendado, ou o poema possa coincidir com a vida, sem que se manifeste a experiência estética. Essa, sim, uma preocupação perceptível nos seus quarenta anos de poesia do poeta, ficcionista, crítico e professor português.

22 JÚDICE, 2010, p. 135. 


\section{Referências}

ALVES, Ida. A poética de Nuno Júdice: Lirismo, subjetividade e paisagens. In: ALVES, Ida; MAFFEI, Luís (Org.). Poetas que interessam mais: leituras da poesia portuguesa pós-Pessoa. Rio de Janeiro: Beco do Azougue, 2011. p. 291-312.

BERARDINELLI, Alfonso. Poesia e gênero lírico: vicissitudes pósmodernas. In: BERARDINELLI, A. Da poesia à prosa. Trad. Maurício Santana Dias. São Paulo: Cosac Naify, 2007. p. 175-190.

DIOGO, Américo António Lindeza. Modernismos, pós-modernismos, anacronismos - para uma História da Poesia Portuguesa Recente. Lisboa: Edições Cosmos, 1993.

JÚDICE, Nuno. Obra poética (1972-1985). Lisboa: Quetzal Editores, 1999.

JÚDICE, Nuno. Guia de conceitos básicos. Lisboa: Publicações D. Quixote, 2010.

JÚDICE, Nuno. Poesia reunida (1967-2000). Lisboa: Edições Dom Quixote, 2000.

GUSMÃO, Manuel. Tatuagem E Palimpsesto - da poesia em alguns poetas e poemas. Lisboa: Assírio \& Alvim, 2010. 


\section{Resumo}

Propõe-se uma leitura da poesia mais recente de Nuno Júdice em Linhas de Água (2000) e Guia de Conceitos Básicos (2010), estabelecendo-se uma relação entre a reflexão sobre os processos da lírica na contemporaneidade e o aproveitamento das experiências do sujeito como matéria poética. Nesse sentido, destacam-se tanto os procedimentos de linguagem quanto as conexões do sonho, da imaginação e de um pensamento sobre as poéticas ocidentais como elementos constituintes de uma lírica singular.

\section{Abstract}

This article intends to accomplish a poetry reading latest Nuno Júdice in Linhas de Água (2000) and Guia de Conceitos Básicos (2010), establishing a link between the processes of reflection on the contemporary and lyrical use of personal experiences subject matter in poetic materialization. Accordingly, we highlight both the language and procedures of the connections of dream, imagination and thinking about the Western poetic traditions as components of a single lyric. 